\title{
Fluorescent imaging of bacterial infections and recent advances made with multimodal radiopharmaceuticals
}

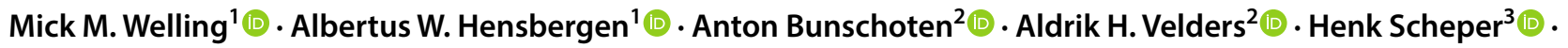

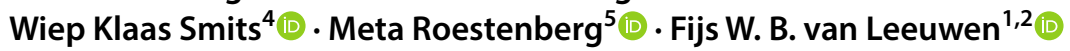

Received: 20 February 2019 / Accepted: 20 March 2019 / Published online: 2 April 2019

(c) The Author(s) 2019

\begin{abstract}
Background Today, both radioactive SPECT and PET imaging radiopharmaceuticals are used for clinical diagnosis of bacterial infections. Due to the possible applications in image-guided surgery, fluorescent imaging of infections has gained interest. We here present the highlights and recent developments in the use of fluorescence imaging for bacterial infections. In this overview, we also include the latest developments in multimodal bacterial imaging strategies that combine radioactive and fluorescent imaging. Based on this literature, we present our future perspectives for the field including the translational potential.

Methods In the current review, we complement earlier reports with the most recent fluorescent and multimodal radiopharmaceuticals for bacterial infection imaging. Where possible, in this review, the chemical structure of the compounds and clinical images were shown.

Results A total of 35 out of 77 original articles on pre-clinical and clinical imaging of bacterial infections with fluorescent tracers and multimodality radiopharmaceuticals were included for reviewing.

Conclusion In our view, the highest translational potential lies with compounds that are based on targeting vectors that are specific for bacteria: e.g., fluorescently labelled $\mathrm{UBI}_{29-41}$, polymyxin $\mathrm{B}$, vancomycin, ZnDPA and a M. tuberculosis-specific $\beta$-lactamase-cleavable linker CNIP800. Multimodal concepts using dually labelled $\mathrm{UBI}_{29-41}$, vancomycin, and ZnDPA help connect optical imaging to the more traditional use of radiopharmaceuticals in infectious diseases. Multimodal bacterial imaging is a promising strategy not only to diagnose bacterial infections but also to evaluate the effectivity of surgical treatment for infections.
\end{abstract}

Keywords Bacterial infection $\cdot$ Fluorescence imaging $\cdot$ Molecular imaging $\cdot$ Radioactivity $\cdot$ Infectious diseases

Mick M. Welling

m.m.welling@lumc.nl

1 Interventional Molecular Imaging Laboratory, Department of Radiology, Leiden University Medical Center, Leiden, The Netherlands

2 Laboratory of BioNanoTechnology, Department of Agrotechnology and Food Sciences, Wageningen University and Research, Wageningen, The Netherlands

3 Department of Internal Medicine and Infectious Diseases, Leiden University Medical Center, Leiden, The Netherlands

4 Section Experimental Bacteriology, Department of Medical Microbiology, Leiden University Medical Center, Leiden, The Netherlands

5 Department of Parasitology and Infectious Diseases, Leiden University Medical Center, Leiden, The Netherlands

\section{Introduction}

Radiological imaging using computed tomography (CT), magnetic resonance imaging (MRI), X-ray, and/or ultrasound is often employed to localize the infection site and to provide a roadmap for tissue sampling and removal [1]. These imaging techniques, unfortunately, are not specific; they detect anatomical abnormalities in tissues and organs that occur as a result of infection or inflammatory responses caused by other diseases [2]. Reliable differentiation between infection and other pathologies is paramount, not only for the diagnostic process but also during therapeutic interventions. To accommodate such needs, significant efforts have been made to realize molecular imaging in the area of infectious diseases [3, 4]. Tracer developments have predominantly focused on radiopharmaceuticals (recently 
reviewed in [5-8]) and on fluorescent approaches. Optical imaging of bacterial infections in vivo is emerging [9]. Such imaging can occur either using endogenous [10], genetically encoded luciferase or green fluorescent protein [11] or using exogenous fluorescent tracers that target and/or illuminate bacteria $[6,7,12,13]$. As summarized in Table 1, the latter group of tracers can be divided for different families of molecules.

In the current review, we complement earlier reports [6, $7,12,13]$ with the most recent fluorescent and multimodal radiopharmaceuticals for bacterial infection imaging. Where possible, the chemical structure of the compounds and clinical images were shown. In addition, we provide some future perspectives for the field.

\section{Imaging endogenous bacterial fluorescence}

Bacterial endogenous imaging has been introduced and validated as a diagnostic method for detection of bacterial wound colonization or clinical wound infections [28]. Bacteria can be visualized in real time in tissues using a handheld imaging device that emits a low-intensity violet light $(405 \mathrm{~nm})$ that excites bacteria fluorescent either with red or cyan. A case series was described by Hill et al. where they applied the detection of the endogenous fluorescence of bacteria themselves in infected superficial wounds of seven patients [29]. An excitation (UV) light source of $405 \mathrm{~nm}$ on superficial wounds of patients yielded a green fluorescent signal in collagen-containing tissue, a red fluorescent signal for porphyrin-producing bacteria (e.g., S. aureus) and a cyan fluorescent signal for pyoverdine-producing bacteria (e.g., P. aeruginosa) (Fig. 1).

The authors illustrated the potential benefits of using this technique in open wounds, where it may assist the clinicians in confirmation whether a wound is infected at the bedside, accurate sampling of the wounds, and in treatment monitoring [10]. This detection method, despite having the advantage of being independent of the use of exogenous tracers, is limited to bacteria that produces fluorescent molecules on the surface and subsurface of the skin. The detection limit of this method mainly depends on the number of bacteria present in the wounds. A potentially valuable secondary side effect of this technology could be that the UV light used to excite the endogenous fluorophores, potentially applies photodynamic therapy to the bacteria [30].

\section{Imaging bacteria with ZnDPA}

Positively charged zinc(II)-dipicolylamine (ZnDPA) analogues that electrostatically interacts with negatively charged bacterial surfaces were used for radioactive or fluorescence imaging bacterial infections (Table 1) [6]. A multimodal ZNDPA approach described an ${ }^{111}$ In-based compound, consisting of ${ }^{111}$ In-DOTA-biotin/SA/biotin-ZnDPA (biotinylated ZnDPA and the biotinylated chelator DOTA were linked through streptavidin, exact chemical structure unknown). This is not a hybrid radiopharmaceutical, but it was coinjected in mice with a fluorophore (PSVue $\left.{ }^{\circledR} 794\right)$-conjugated ZnDPA analogue (Fig. 2a) as a cocktail at $3 \mathrm{~h}$ after infection/ inflammation. This approach allowed for both SPECT and optical imaging [31]. Imaging with the two compounds combined, discriminated well between bacterial infections and LPS-induced sterile inflammations (Fig. 2b, c). Both the fluorescence and SPECT images showed obvious accumulation in the $S$. pyogenes-infected thigh muscle in both models at 1 , 4 , and $22 \mathrm{~h}$ after injection. At $22 \mathrm{~h}$, the average ratio between infection and control muscle for the radioactive compound was 2.8 (number of bacteria unknown). This ratio was significantly $(p<0.01)$ higher compared to the ratio between LPS-induced sterile inflammations and control muscle, i.e., 1.0. A general limitation of the positively charged ZnDPA is its binding to negatively charged membranes of apoptotic and necrotic mammalian cells, which also makes ZnDPA a marker for the apoptosis/necrosis created by the infection [32].

\section{Imaging infections with fluorescent antimicrobial peptides}

Antimicrobial peptides (AMPs) were designed to rapidly kill a broad spectrum of pathogens, including Gram-positive and Gram-negative bacteria, fungi, parasites, and even enveloped viruses [33]. In low quantities, however, radiolabelled cationic AMPs have been successfully used for bacterial imaging. Cationic AMPs bind to negatively charged lipoteichoic acid, phospholipids, and lipopolysaccharides on bacterial membranes $[34,35]$. The radiolabelled cationic antimicrobial peptide $\mathrm{UBI}_{29-41}$, has found its way into clinical SPECT and PET imaging of infections [36]. The same peptide fragment can also be labelled with the near-infrared (NIR) dye ICG02 (Fig. 3a) and was used to image infections with various Gram-positive and Gram-negative bacteria in mice [37]. A study with $S$. aureus demonstrated the tracer's potential to identify muscles infected with bacteria (Fig. 3b); infectionto-noninfected tissue ratios increased to 5-6 for $S$. aureus at $6 \mathrm{~h}$ p.i., whereas the ratios decreased to almost 1.0 at $48 \mathrm{~h}$. p.i.

In another study, $\mathrm{UBI}_{29-41}$ was conjugated to 7 -nitrobenz2-oxa-1,3-diazol-4yl (NBD, Fig. 4a). This lipophilic fluorescent dye increases in brightness in a dose-dependent fashion upon insertion into the bacterial membrane (Fig. 4b) [38]. The compound was used to detect bacteria in human lung bronchoalveolar lavage fluid and ex vivo in human 


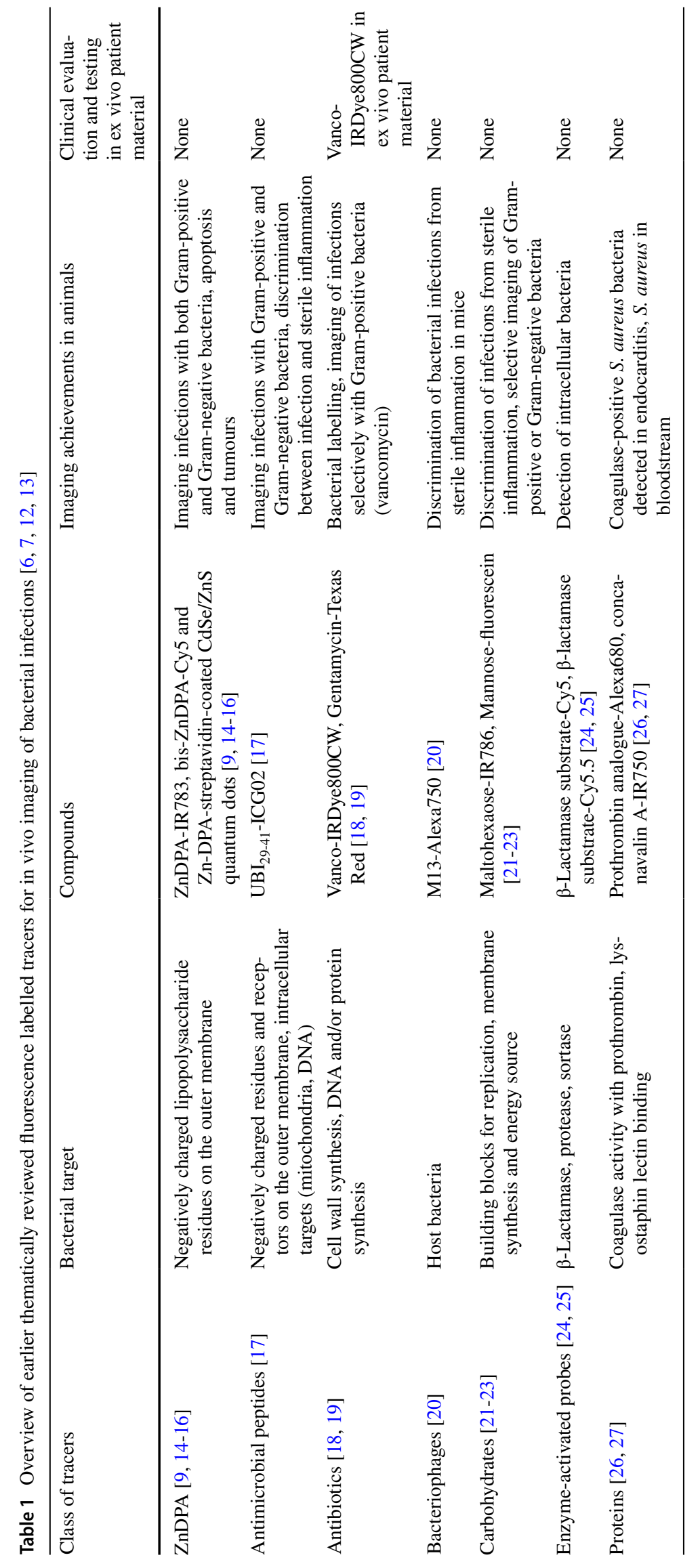




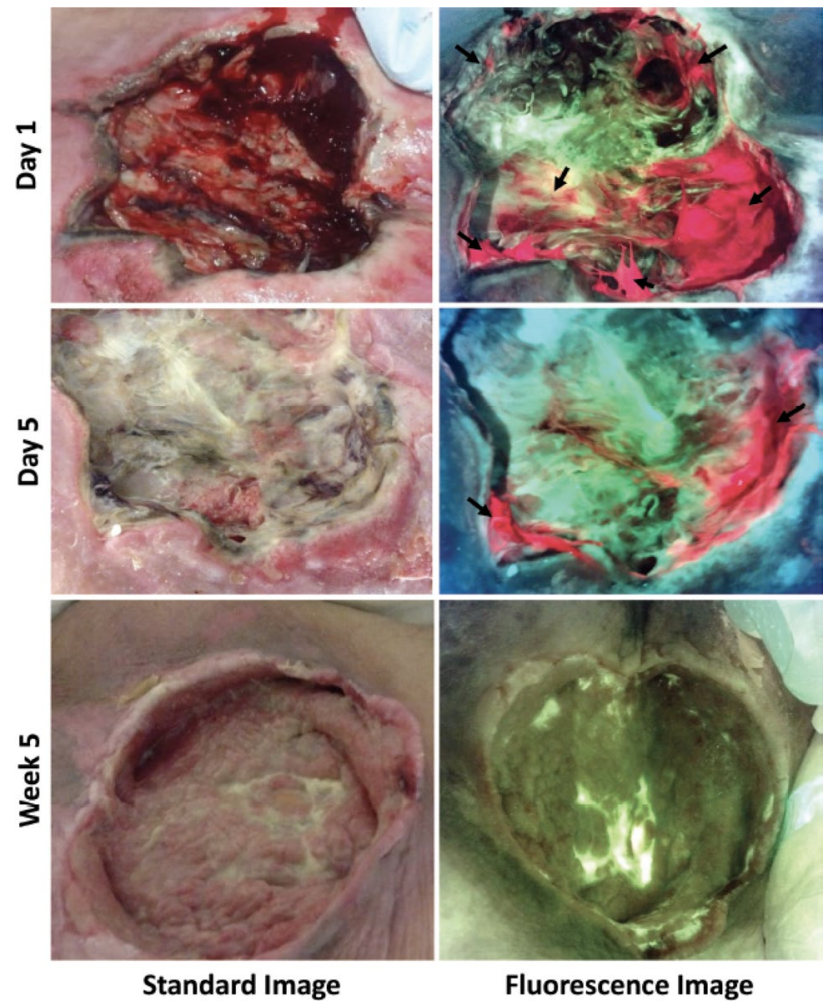

Fig. 1 Patient with a pressure injury. Fluorescence images acquired on day 1 revealed extensive bioburden remaining post-debridement. Bacterial fluorescence appears red/pink on images noted by arrows. Swabs later confirmed heavy growth of M. morganii, E. coli, and E. faecalis. Images also guided additional targeted debridement (sparing noncontaminated regions) on day 5. Images acquired at each subsequent dressing change tracked significant decrease in bioburden. Week 5 images show bacterial (red) fluorescence is no longer present. From: Hill et al. [29]

lung tissue material using fibre-optic confocal fluorescence microscopy (Fig. 4b) [38].
Although the autofluorescence of background tissue disturbed the sensitivity of imaging and increased the detection limit, initial results were promising for imaging bacteria in vivo. Another issue is the chance of proteolysis and oxidation of peptide-based tracers in vivo, and to reduce this complication, a cyclic analogue of the UBI peptide was included in the study as well (Fig. 4c). The imaging results were comparable with the linear variant of the tracer (Fig. 4b, d).

For multimodal imaging, a dual-labelled (radioactive and fluorescent) construct of the bacteria imaging radiopharmaceutical UBI ${ }_{29-41},{ }^{111}$ In-DTPA-Cy5-UBI $29-41$ (Fig. 5a), was described [39]. This radiopharmaceutical allowed radioactive and fluorescence imaging in experimental infections in mice (Fig. 5b). Radioactivity-based measurements yielded target-to-nontarget (T/NT) ratios of $2.82 \pm 0.32$ for $S$. aureus and $2.37 \pm 0.05$ for $K$. pneumoniae, while fluorescence-based measurements of the same compound yielded $2.38 \pm 0.09$ and $3.55 \pm 0.31$, respectively. As with many other infection imaging tracers, all labelled species of $\mathrm{UBI}_{29-41}$ are generic, meaning that they will bind to all types of bacteria; therefore, it cannot differentiate between various strains of pathogens.

\section{Imaging infections with antibiotics}

Fluorescent antibiotics have proven to be useful for studying cell wall synthesis [40] and bacterial resistance, examining toxicity, exploring the mode of action [19] as well as imaging of infections [18]. Recently, Akram et al. presented a study that made use of an NBD-labelled cationic antimicrobial peptide antibiotic polymyxin B sulphate (PMX-NBD, Fig. 6a) [41]—PMX-NBD binds to lipid A of the lipopolysaccharides in the outer membrane of Gram-negative bacteria [42]. Using an in situ endomicroscopy set-up, the authors were able to specifically visualize Gram-negative bacteria in
A

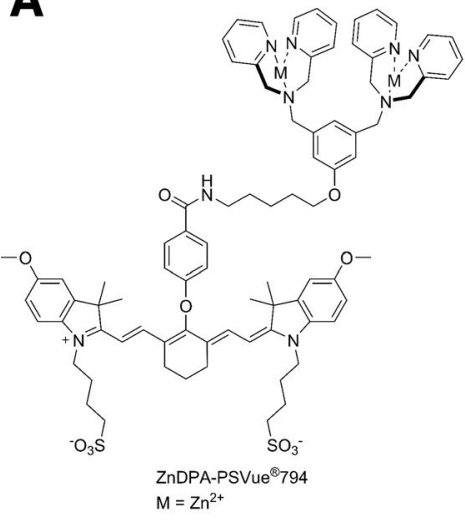

B

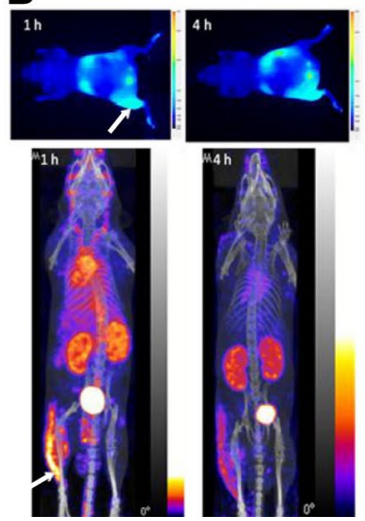

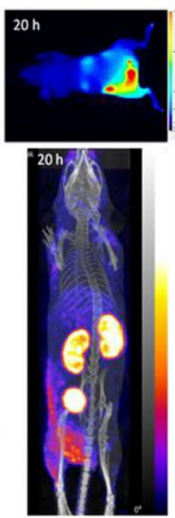

C
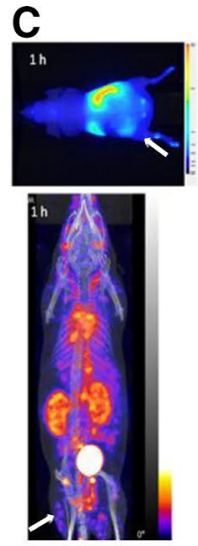
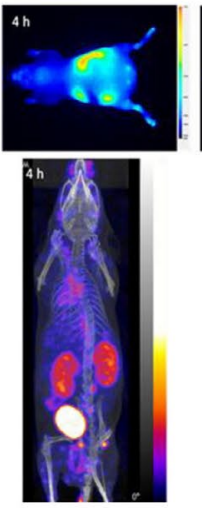

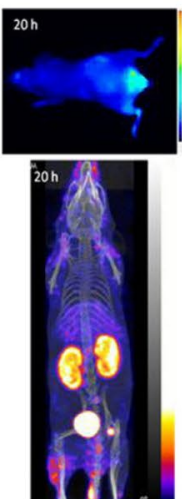

Fig. 2 a Chemical structure of PSVue ${ }^{\circledR} 794$-conjugated ZnDPA. Optical images (top panels) and projections of SPECT/CT acquisitions (bottom panels) of $\mathbf{b}$ a $S$. pyogenes-infected mouse and $\mathbf{C}$ ) LPS- induced inflammation mouse at 1,4 and $20 \mathrm{~h}$ post-administration of a cocktail consisting of DPA-PSVue ${ }^{\circledR} 794$ and ${ }^{111}$ In-DOTA-ZnDPA. Arrow indicates the infection/inflammation sites. From: Liu et al. [31] 


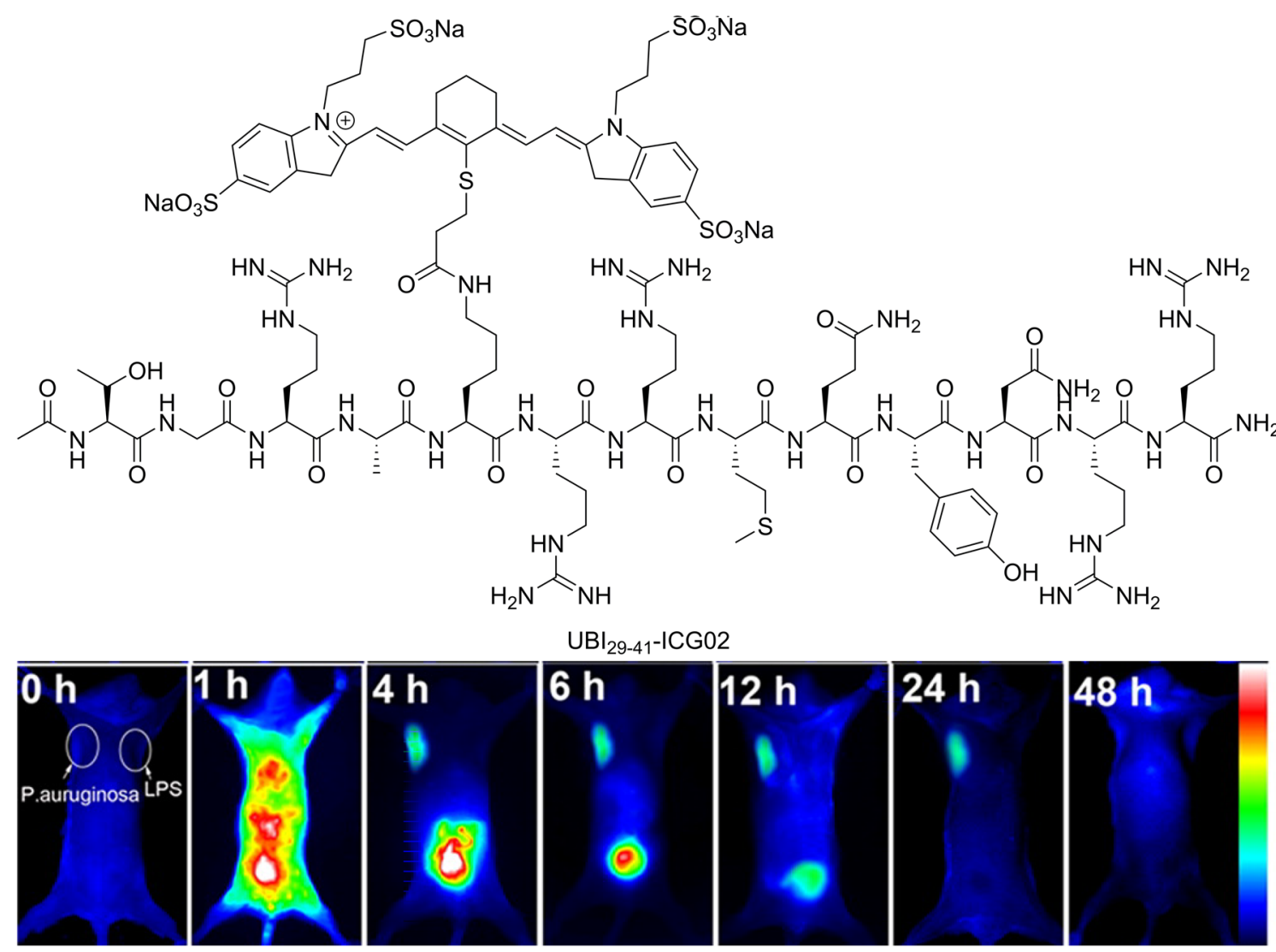

Fig. 3 a Chemical structure of $\mathrm{UBI}_{29-41}-\mathrm{ICG} 02$ and $\mathbf{b}$ NIR fluorescence images of $\mathrm{UBI}_{29-41}-\mathrm{ICG}_{2}$ after injecting into mice infected with $S$. aureus (right) and LPS (left). From: Chen et al. [37]

ex vivo ventilated ewes' lungs (Fig. 6b). The same real-time imaging technique also proved to be efficient in distal lungs of six human bronchiectasis patients (Fig. 6c). Especially for pulmonary infections with Gram-negative bacteria, this imaging modality proved to be more specific and sensitive than the alternative bronchoalveolar lavage and bacterial culturing [43].

A particularly interesting example is the use of fluorescein-labelled vancomycin (Fig. 7a). Vancomycin inhibits synthesis and assembly of the thick peptidoglycan layer in Gram-positive bacteria and is active against Grampositive bacteria only. Therefore, it is a specific imaging agent restricted to only Gram-positive bacteria. In mice with $S$. aureus-infected thigh muscles, this tracer allowed discrimination between infections with Gram-positive and Gram-negative bacteria (E. coli). Also, discrimination of bacterial infection from sterile inflammation was assessed (Fig. 7b) [18]. In a human post-mortem implant model, a tissue implant containing labelled bacteria was inserted subcutaneously and thereafter imaged. Clearly, spots containing fluorescent bacteria could be identified (Fig. 7c).

The use of fluorescein-labelled vancomycin is limited by the inability to detect deep tissue infections because of scattering and absorption of photons by tissue. To overcome this limitation, a hybrid vancomycin-based radiopharmaceutical was introduced that contained the fluorescent dye rhodamine $\mathrm{B}$ as well as the radioisotope ${ }^{125} \mathrm{I}$ (creating ${ }^{125}$ I-Rho-vancomycin) (Fig. 7d) [44]. Mice were infected in the right thigh muscle with methicillin-resistant S. aureus (MRSA), whereas the contralateral thigh muscle was infected with $E$. coli reflecting the bias in labelling Gram-positive bacteria. Within $2 \mathrm{~h}$ after injection, ${ }^{125}$ I-Rho-vancomycin showed an 8.7-fold higher accumulation in MRSA-infected thigh muscles than in muscles infected with E. coli. (Fig. 7e). Fluorescence imaging revealed a 3.9-fold increase in uptake in MRSA-infected thigh muscles with ${ }^{125}$ I-Rho-vancomycin compared to control tissue (Fig. 7f). Imaging of pulmonary infections by MRSA with ${ }^{125}$ I-Rho-vancomycin yielded about 8.9- to 13.3-fold higher lung-to-background ratios than a control radiopharmaceutical (non-cell binding variant of ${ }^{125} \mathrm{I}$-Rhovancomycin). This study underlines that ${ }^{125} \mathrm{I}$-Rho-vancomycin allows accumulation on bacterial membranes of Gram-positive bacteria. 

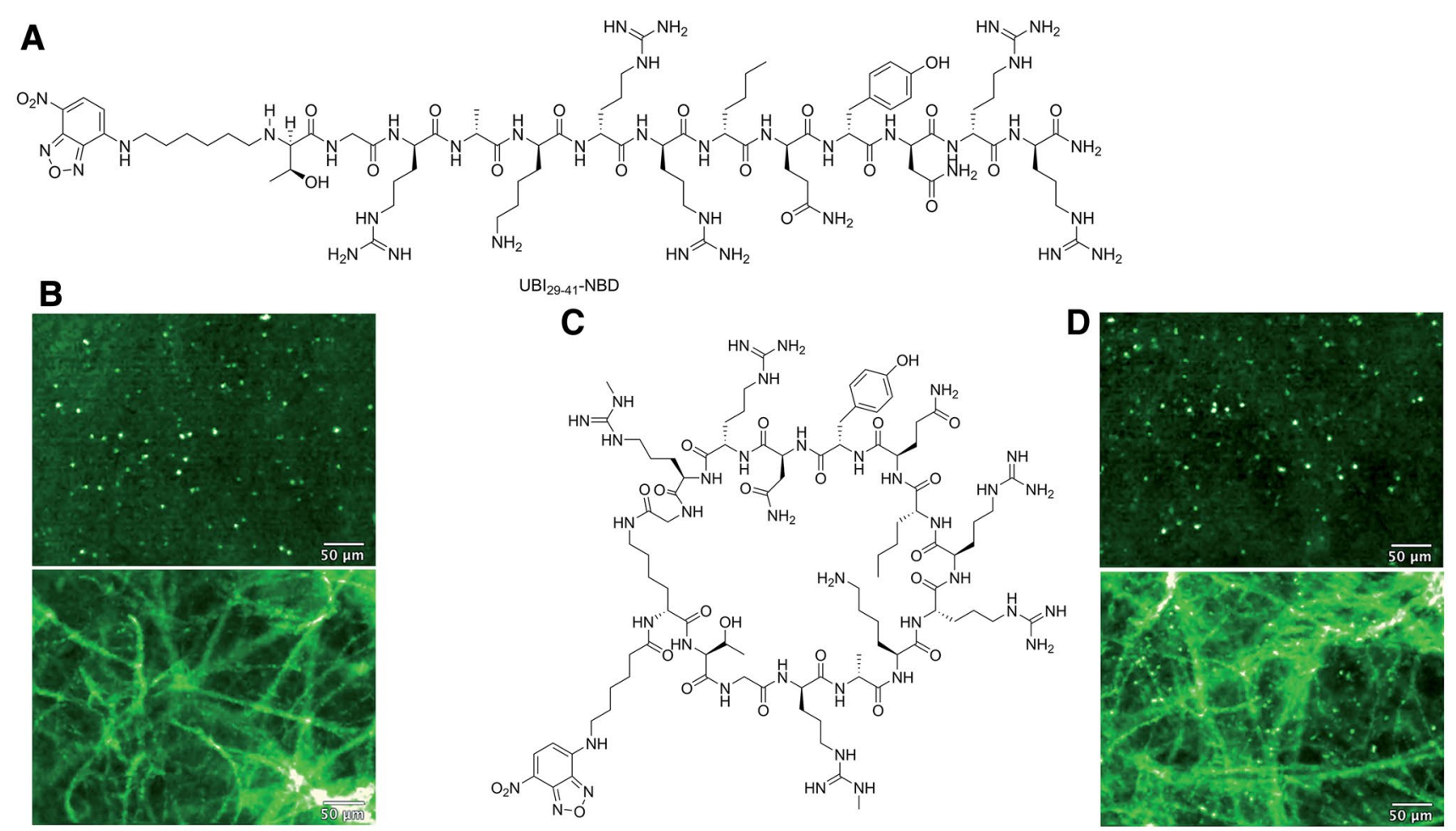

Fig. 4 a Chemical structure of $\mathrm{UBI}_{29-41}-\mathrm{NBD}$ and $\mathbf{b}$ imaging of bacteria in ex vivo human lung tissue by fibred confocal fluorescence microscopy (FCFM). FCFM imaging of bacteria in suspension (upper panels) or when co-incubated with ex vivo human lung tissue (lower panels). Upper panels show $\mathrm{UBI}_{29-41}$-NBD can image bacteria in sus-

\section{Imaging bacteria with enzyme-activated tracers}

Recently, activatable fluorescent tracers show a promising development that allows fast and specific testing of the metabolic processes of specific strains of bacteria [6]. These tracers allow detection of bacteria expressing nuclease, reductase or hydrolyse activities.

Nucleases, which have widespread expression and diversity, are one category of enzymes that is expressed by various bacterial species capable of cleaving the phosphodiester bonds between nucleotides of nucleic acids which is of importance for many aspects in DNA repair [45]. For imaging of micrococcal nuclease as produced by $S$. aureus [46], a substrate consisting of a short partially $O$-methylmodified oligonucleotide (mC-mU-mC-mG-T-T-mC-mGmU-mU-mC) flanked with a fluorescein amidite (FAM) or Cy5.5 fluorophore and ZEN ${ }^{\mathrm{TM}}$ fluorescence quencher (IDT DNA Technologies) (Fig. 8a) was used. Both tracers were activated in vitro upon enzymatic cleaving by 26 clinical $S$. aureus isolates but were resistant to serum nucleases. In a mouse model bearing $S$. aureus-induced muscle infection, both FAM and Cy5.5 substrates were pension but not in the presence of ex vivo human lung. Right panels demonstrate c cyclic $\mathrm{UBI}_{29-41}$-NBD (UBI 11) can d image bacteria by FCFM in the presence of ex vivo human lung with a characteristic small round, punctate fluorescence. All compounds at $10 \mu \mathrm{M}, n=3$. From: Akram et al. Chem Sci. 2015;6:6971-6979 injected intravenously and yielded activation by bacteria and allowed imaging of the infection (Fig. 8b) [47].

Nitroreductases (NTR) are enzymes that allow bacteria to metabolise nitroaromatic compounds. These enzymes are expressed in most Gram-positive and Gram-negative bacterial strains [48]. The self-quenched NIR dye CytoCy5 $\mathrm{S}^{\odot}$ (Fig. 9a) was intravenously injected and it was reported to generate a signal that allowed detection of $5 \times 10^{6}$ viable S. typhimurium in experimental thigh muscle infections in mice as well as in the same model of infection with $5 \times 10^{6}$ viable $E$. coli [49]. As the bacteria used in these studies were engineered to be luminescent, this allowed for imaging using both bioluminescence and fluorescence. As certain tumours also express NTR, these fluorogenic NTR substrates can also be used for imaging of tumours $[49,50]$. As nitroreductases are also expressed in eukaryotic cells, for imaging of infections this may increase the background activity.

For the detection of pulmonary M. tuberculosis infections, $\beta$-lactamase-activatable tracers can be applied as an activatable ligand for bacterial enzymes [6, 25]. A NIR reporter enzyme fluorogenic substrate for $\beta$-lactamase (CNIR5, Fig. 10a) consists of a fluorescent dye IRDye $800 \mathrm{CW}$ and a fluorescence quencher (QC-1) linked to each other via a $M$. 
Fig. 5 a Chemical structure of ${ }^{111} \ln$-DTPA-Cy5-UBI $29-41$. b Typical in vivo imaging of $S$. aureus infections with ${ }^{111}$ ln-DTPA-Cy5-UBI ${ }_{29-41}$ in the paw muscle in mice; images are obtained from paws infected with bacteria $1 \times 10^{7} \mathrm{CFU}$ of bacteria at $2 \mathrm{~h}$ after injection of the radiopharmaceutical. On the anterior images, infected muscles are indicated with oval shapes and the contralateral noninfected muscles are indicated with dotted oval shapes. A CT scan of a mouse was included to clarify the anatomical localisation of the infected tissues. From: Welling et al. [6]

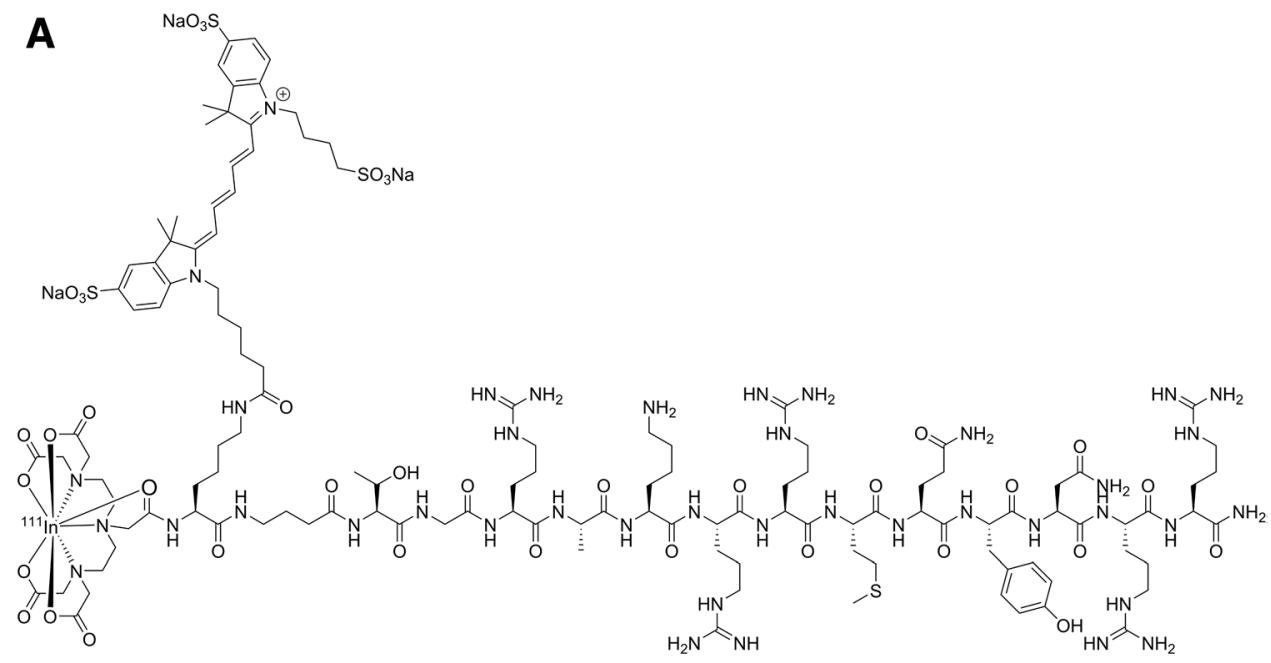

B
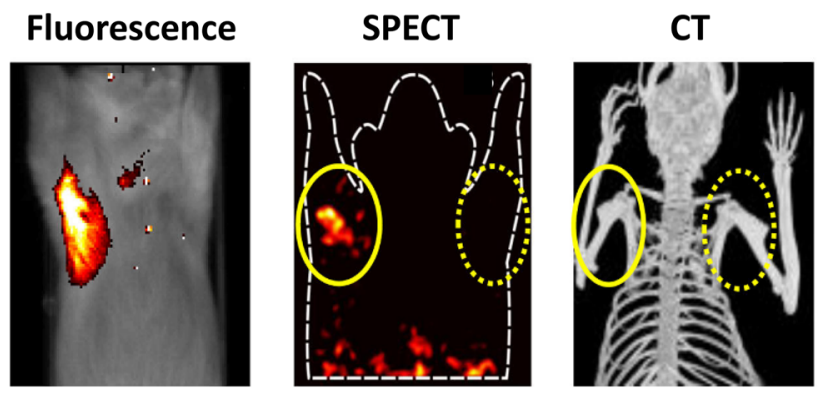

tuberculosis-specific $\beta$-lactamase-cleavable linker [24] that is quenched by Förster resonance energy transfer (FRET) with the quencher molecule and becomes fluorescent after cleavage of the $\beta$-lactam ring by intracellular $M$. tuberculosis, separating the quencher from the dye and thus cancelling the FRET (Fig. 10b). This approach allowed for the detection of viable $M$. tuberculosis in the lungs of mice using NIR tracer CNIR800 (Fig. 10c) [25, 51, 52].

The advantage of enzyme-activatable tracers is that it has potency in imaging of infections with drug-resistant bacteria [53].

\section{Imaging of bacterial proteins}

Bacteria cell walls and membranes contains various proteins that are essential for maintenance of their external structure and integrity. As some of these proteins are solely expressed by bacteria, they are of interest in targeting by fluorescent tracers.

The carbohydrate-binding protein (lectin) concanavalin A, has a high affinity for mannose residues present in bacterial cell walls. The plant-derived lectin concanavalin A binds $\alpha$-D-mannosyl and $\alpha$-D-glucosyl residues of B-glycans. When concanavalin A was conjugated to poly( $N$-isopropylacrylamide microspheres PNIPAM-co-St which were functionalised with the NIR dye IR750 (chemical structure unknown) [27], this compound has shown to allow for imaging in a murine wound and catheter infection model with $S$. aureus. Following topical application and washing in live mice, the tracer rapidly displayed the presence of bacteria in the wounds and catheters already from $2 \times 10^{6}$ viable bacteria with the infection-to-background ratios ranging between 2 and 5. Unfortunately, concanavalin A interacts with all mannose-containing proteins and receptors, [54] e.g., those present in erythrocytes and various cancer cells $[54,55]$.

\section{Imaging of bacterial metabolic activity}

Siderophores, consisting of metal-chelating peptides, are low-molecular mass iron binders transported by most bacteria, fungi, and some plants [56]. Because bacteria require iron for their metabolism and growth, uptake of iron was via siderophores, and the labelled siderophores will lead to labelled bacteria. Ferreira et al. demonstrated that siderophore-Cy5.5 conjugates (Fig. 11a) yielded different intensities in uptake in various bacterial species. This was related to differences in iron transportation by various species of bacteria with different growth phases and metabolism. In vivo fluorescence imaging of $P$. aeruginosa skin infections (in mice) showed imaging of infections with the highest intensity at 


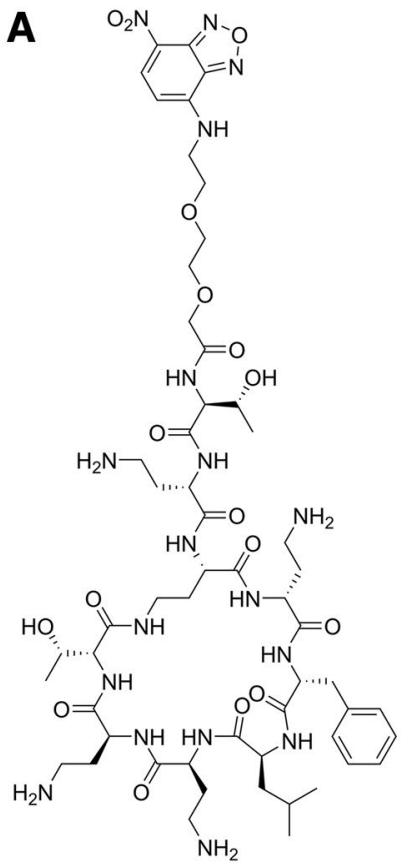

Polymyxin B sulphate-NBD
B

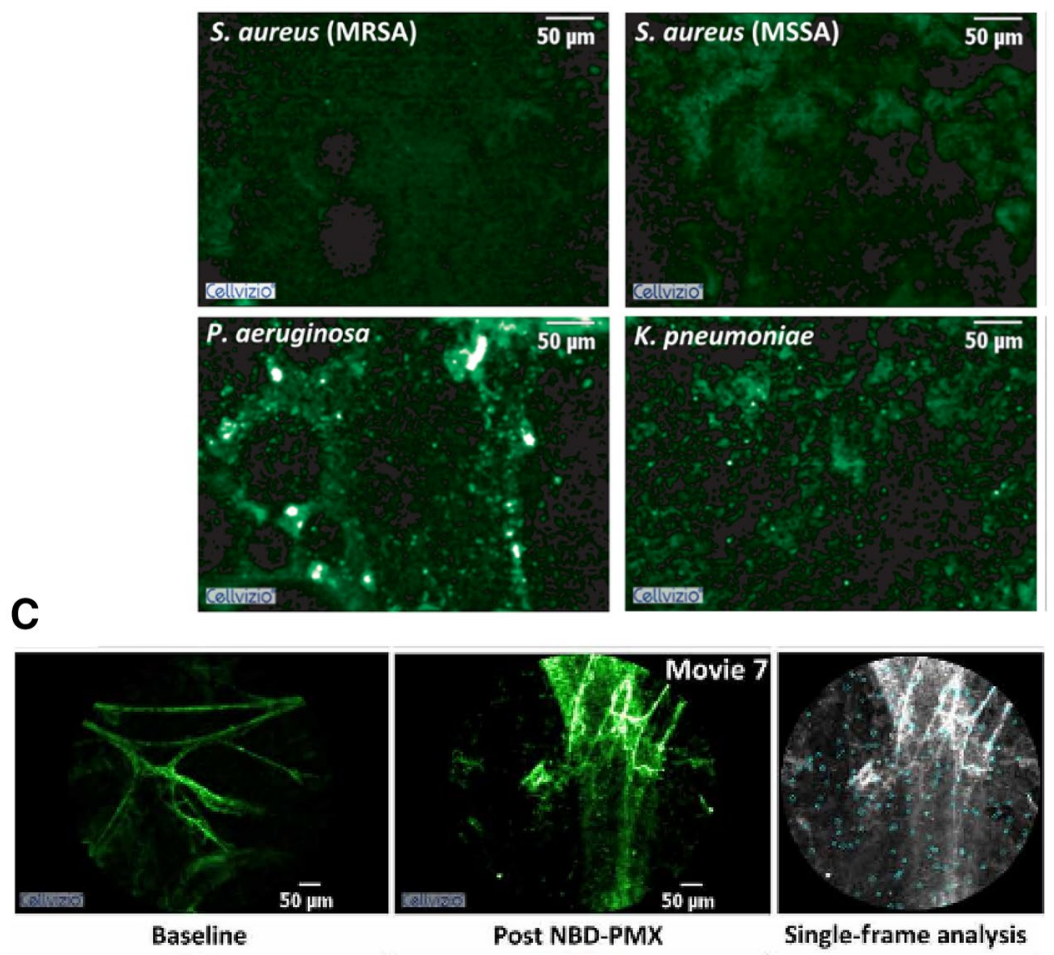

Fig. 6 a Chemical structure of polymyxin B sulphate-NBD (PMXNBD). b PMX-NBD labels Gram-negative, but not Gram-positive, bacteria in situ in ex vivo ovine lungs. Representative optical endomicroscopy images of Gram-positive and Gram-negative segments.

$0.6 \mathrm{~h}$ after injection of the tracer (Fig. 11b) [57]. At later intervals until $24 \mathrm{~h}$ p.i., the fluorescence signal decreased. In control mice injected with a tracer lacking the catechol (siderophore) moiety, because of clearance, the fluorescent signal was only noted in the kidneys (Fig. 11b).

\section{Other bacteria-imaging tracers}

Kim et al. discovered a fluorescent tracer that binds to fibrils that are part of the bacterial biofilm matrix $[58,59]$ together with extracellular polymeric substances like DNA, proteins and polysaccharides [60]. Biofilm-associated infections like prosthetic joint infections or chronic osteomyelitis are very difficult to treat, because the biofilm protects bacteria against the host immune response and a subpopulation of bacteria residing in the biofilm switch to a dormant state. Biofilm-penetrating tracers are of interest in the detection of persistent and chronically infected tissues and implants and may serve as an alternative for tracers that cannot pass the biofilm and thus fails in targeting bacteria. The boron-dipyrromethene (BODIPY)-based fluorescent compound called CDy11, was obtained by screening for functional binding to c NBD-PMX labels $S$. pneumoniae in humans when administered endobronchially and imaged with optical endomicroscopy. From: Akram et al. [41]

bacterial biofilms in vitro (Fig. 12a). Although this tracer is not targeted against the bacteria themselves and requires a formed biofilm to show binding, the authors showed that the tracer in a corneal infection model accumulated in fibril-like structures in biofilms of bacterially infected eyes (Fig. 12b).

\section{Discussion and future perspectives}

Differentiation between infectious and non-infectious causes of inflammatory processes is of crucial importance for clinicians. For this purpose, progress has been directed towards specific targeting of pathogens. In the current review, we updated earlier reviews with new findings on fluorescent and even multimodal radiopharmaceuticals for imaging of bacterial infections. Fluorescence imaging alone holds particular promise for the inspection of human body surfaces of, e.g., surgical wounds $[12,13]$. Hybrid radiopharmaceutical analogues, on the other hand, provide outcome and help connect fluorescence tracers with their translationally more advanced radionuclear counterparts. With hybrid radiopharmaceuticals, the radioactive imaging is the best total body-imaging modality for detecting and localizing deep infections, 


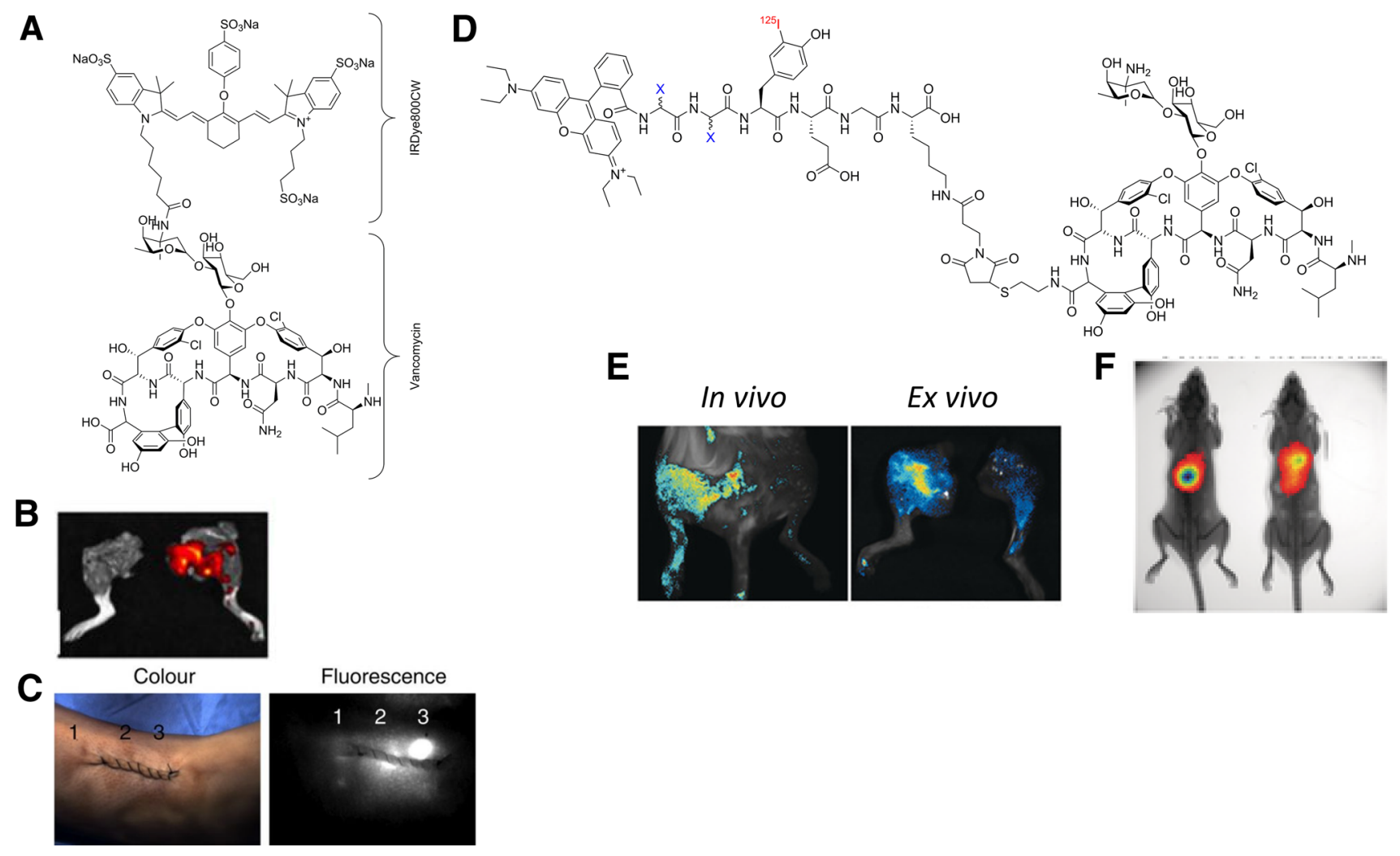

Fig. 7 a Chemical structure of vanco-800CW. b Ex vivo fluorescence imaging of $S$. aureus (left limb) and E. coli (right limb) with vanco-800CW. c Vanco-800CW-labelled S. aureus were spotted onto a Whatman paper strip, which was imaged after surgical application onto the distal tibia of a post-mortem ankle. The tested amounts of $S$. aureus applied to the Whatman paper were: $1 ; 0.63 \times 10^{8}, 2$; $1.25 \times 10^{8}, 3 ; 2.5 \times 10^{8}$ CFU. From: van Oosten et al. [18]. d Chemi-

whereas fluorescence imaging allows real-time imaging and has a high spatial resolution $[61,62]$. This innovative concept has already been applied in oncological surgery where it provides full-body nuclear imaging to roughly locate the lesions and aids the surgeon during inspection of the primary tumour and searching for microscopical metastasis guided by a fluorescent signal [63-67]. In imaging of infections, there is a need to combine nuclear and optical imaging radiopharmaceuticals as well as ideally, one single dual-modal compound could be administered to (i) assess total disease and infection burden using nuclear imaging techniques, followed by (ii) identification of the extent of the infection, and prevention of sampling errors. For example, in wound and trauma surgery, infections often occurs and in this respect, the optical modality can be used to visualize the localization of the bacteria and thus facilitates complete resection during surgical debridement of infected areas. A similar approach is feasible, after a surgical intervention and inspection, persistent infections of transplants can be detected using the visual signal. Such a dual-modal compound could be especially attractive to minimize patient burden and healthcare costs; as cal structure of ${ }^{125} \mathrm{I}-\mathrm{Rho}-\mathrm{Van}(\mathrm{X}=\mathrm{CH} 2 \mathrm{Ph})$ and the control radiopharmaceutical $(X=H 2)$. e In vivo and ex vivo fluorescence imaging of infected mouse with MRSA-induced myositis in the left hind leg and $E$. coli-induced myositis in the right hind leg $2 \mathrm{~h}$ after i.v. injection. f In vivo SPECT imaging with ${ }^{125} \mathrm{I}-\mathrm{Rho}$-Van in mice with MRSA pneumonia (overlay of X-ray and isotope signals). From: Yang et al. [44]

imaging is immediately followed by image-guided surgery within a short time frame, it can accelerate improvement of health status and costs on healthcare. Recent data shows that bacterial imaging is slowly finding its way into ex vivo human applications. As this type of progression is similar to what has been observed for infection-specific radiopharmaceuticals [68], this illustrates that fluorescence-based bacterial imaging is also steadily moving towards medical implementation and can ultimately be used for guiding surgical interventions.

Tissue attenuation, e.g., absorption of scattering of the light is a restrictive factor during the pharmacological evaluation of fluorescent tracers. Although it is known that fluorescent labels can influence tracer pharmacokinetics [69, 70], this effect cannot be quantified without having a radioisotope for quantitative imaging/biodistribution assessments.

Next to the traditional use of organic dyes, inorganic dyes may also be used in the future as these may differ in pharmacokinetics or the number of attached reporter groups. The introduction of inorganic medicinal chemistry is making rapid progress, with enormous impact, e.g., with 

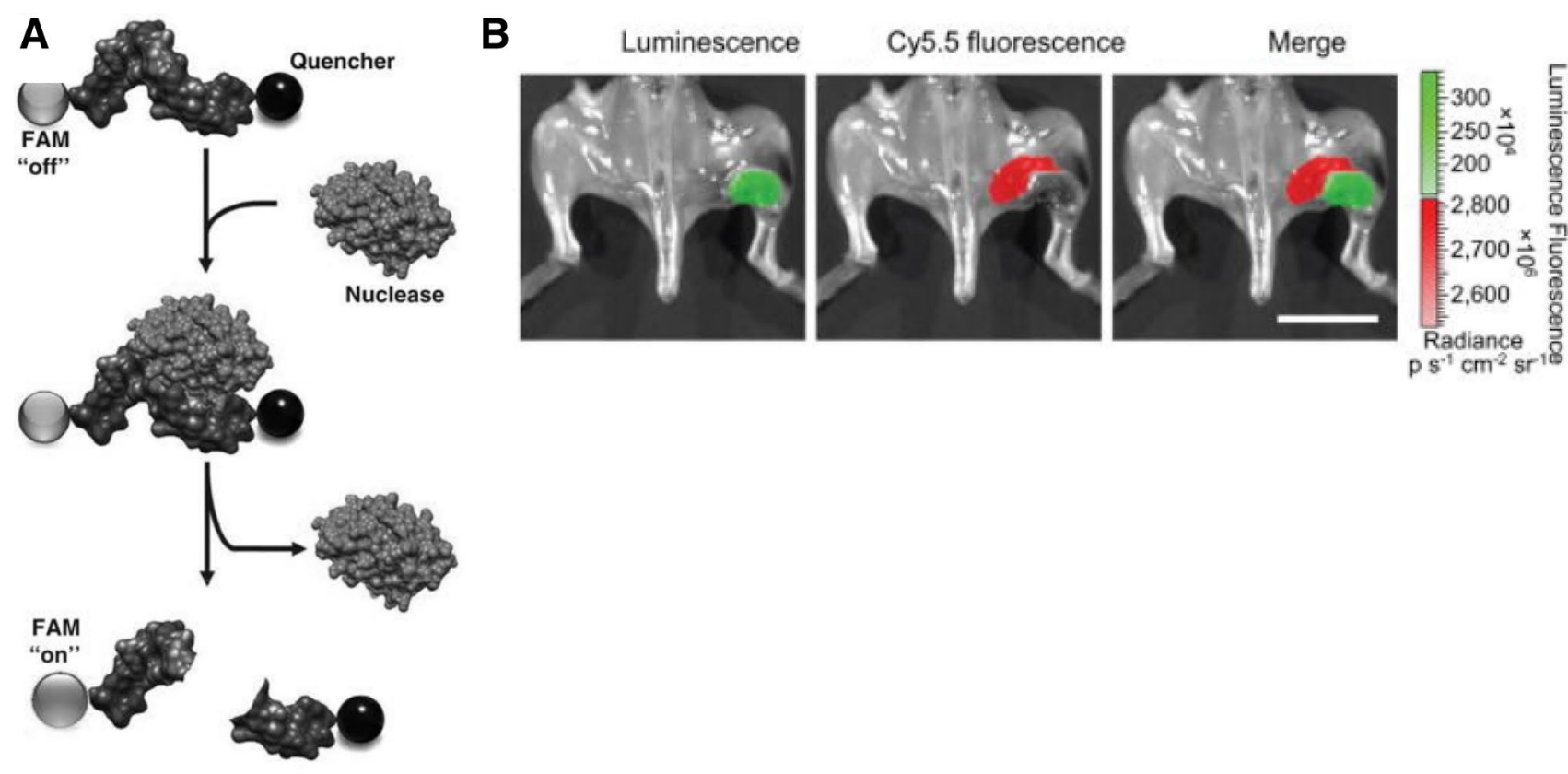

Fig. 8 a The basis for nuclease detection with RNase substrates is illustrated. RNA oligonucleotides (5'-UCUCGUAC-GUUC-3') with chemically modified nucleotides, labelled on the $5^{\prime}$ ends with fluorescein amidite (FAM) are not fluorescent due to the close proximity of a $3^{\prime}$-quencher to the FAM. Upon degradation of the oligo, the quencher diffuses away from the FAM and the FAM exhibits green fluorescence. From Hernandez et al. Nucleic Acid Ther
2012;22(1):58-68. b Imaging of micrococcal nuclease activity of $S$. aureus in mice. For post-sacrifice and dissection imaging, mice with thigh muscle lux,$+ \mathrm{MN}$-expressing $S$. aureus pyomyositis, injected with Cy5.5-TT were sacrificed 45 min after probe injection; dissected muscle tissue was imaged with luminescence and the Cy5.5 fluorescence channel. Scale bars $=1 \mathrm{~cm}$. From: Hernandez et al. Nat Med. 2014;20(3):301-306

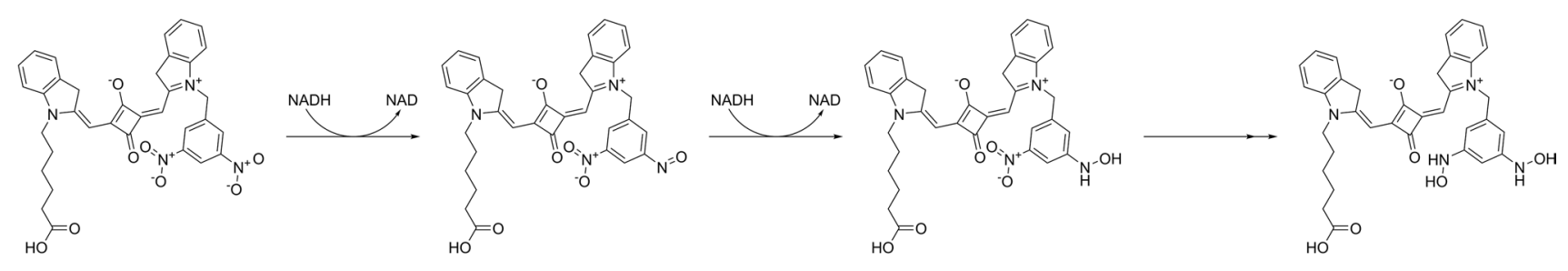

Fig. 9 Proposed mechanism of CytoCy5S $\mathrm{S}^{\odot}$ "activation" by NTR. Reduction of the dinitro aryl quenched substrate to mono- and dihydroxylamine products via nitroso intermediate. From: Emmet McCormack et al. Cancer Res. 2012;73(4):1276-1286

platinum-based compounds in antitumor chemotherapy, and iron oxides and gadolinium(III) compounds in MRI contrast agents for noninvasive diagnostics [71]. Several transition metal complexes (in particular those with ruthenium(II)) have been explored for targeted fluorescent imaging [72], including lifetime imaging [73-76]. Uniquely, these inorganic dyes may also support theranostic applications due to their ability to create reactive singlet oxygen $[75,77]$. Within the context of multimodal imaging, it is interesting to note that transition metal ions such as ruthenium can also be replaced with radioactive isotopes, e.g., ${ }^{97} \mathrm{Ru}[78]$, further extending the scope of inorganic medicinal compounds in which, uniquely, one and the same metal ion could act as the photophysically and/or photochemically active centre, as well as the radioactive nuclide for tracing or therapy. Importantly, combining multiple properties into a single molecular (sub)unit, dramatically alleviates the negative effects of multiple bulky molecular sub-units on targeting and uptake properties.

Developments in imaging of bacterial infections with fluorescent, radioactive [68] or multimodality radiopharmaceuticals are still in progress and besides generic tracers that can image the site of infections, improvements in sensitivity were also made that allows to assess the bacterial burden. Also, imaging of specific bacterial strains can be very helpful as a tool for imaging of pathogens in environments which colonized with other bacteria as in the gut or the lungs. In our view, the highest translational potential 


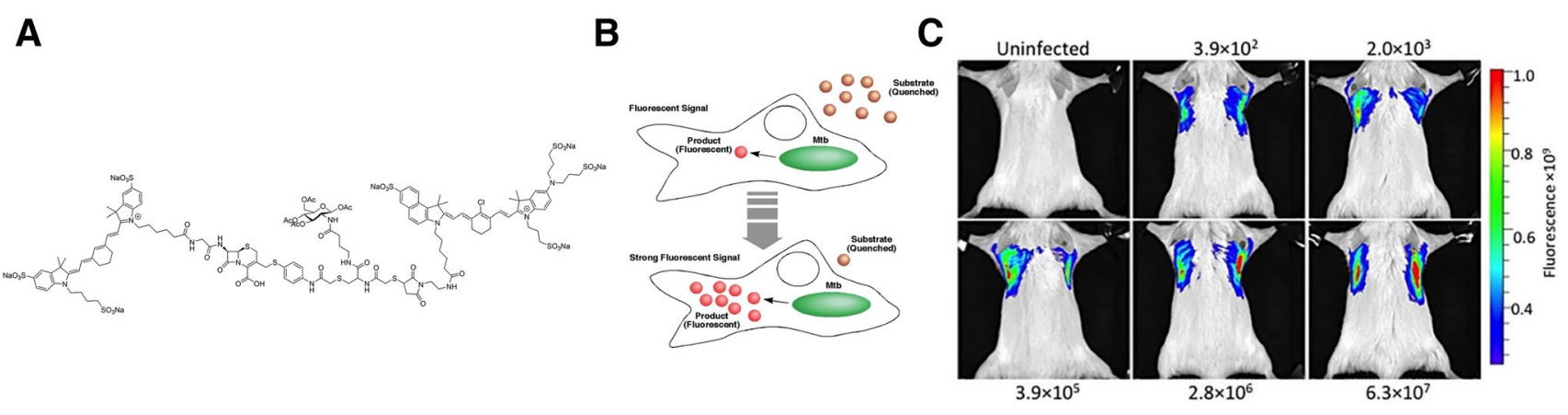

Fig. 10 a Chemical structure of CNIR5; IRDye $800 \mathrm{CW}$ is linked to a quencher (QC-1) via a lactam ring, which can be hydrolyzed by $M$. tuberculosis $\beta$-lactamase. b Proposed model that outlines the high sensitivity of REF. The substrate (CNIR5) is cleaved to a product by intracellular M. tuberculosis. The product (Cy5.5) is retained within the host cell and builds up to very high levels until the substrate is no longer available. From Kong et al. Virulence 2010;1(6):558-562. c Mouse whole-body images taken using trans-illumination at $6 \mathrm{~h}$ postadministration of CNIR800 with various numbers of viable bacteria in the lungs. From: Yang et al. [51]
Fig. 11 a Chemical structure of siderophore-Cy5.5. b Mouse model for the diagnosis of subcutaneous bacterial infections by siderophore-Cy5.5 conjugate. $P$. aeruginosa (left and right) indicated by dashed white ovals (Bac) uninfected animals (Ctr). The fluorescence images were recorded after 0.6 , 3,5 , and 24 h. From: Ferreira et al. [57]
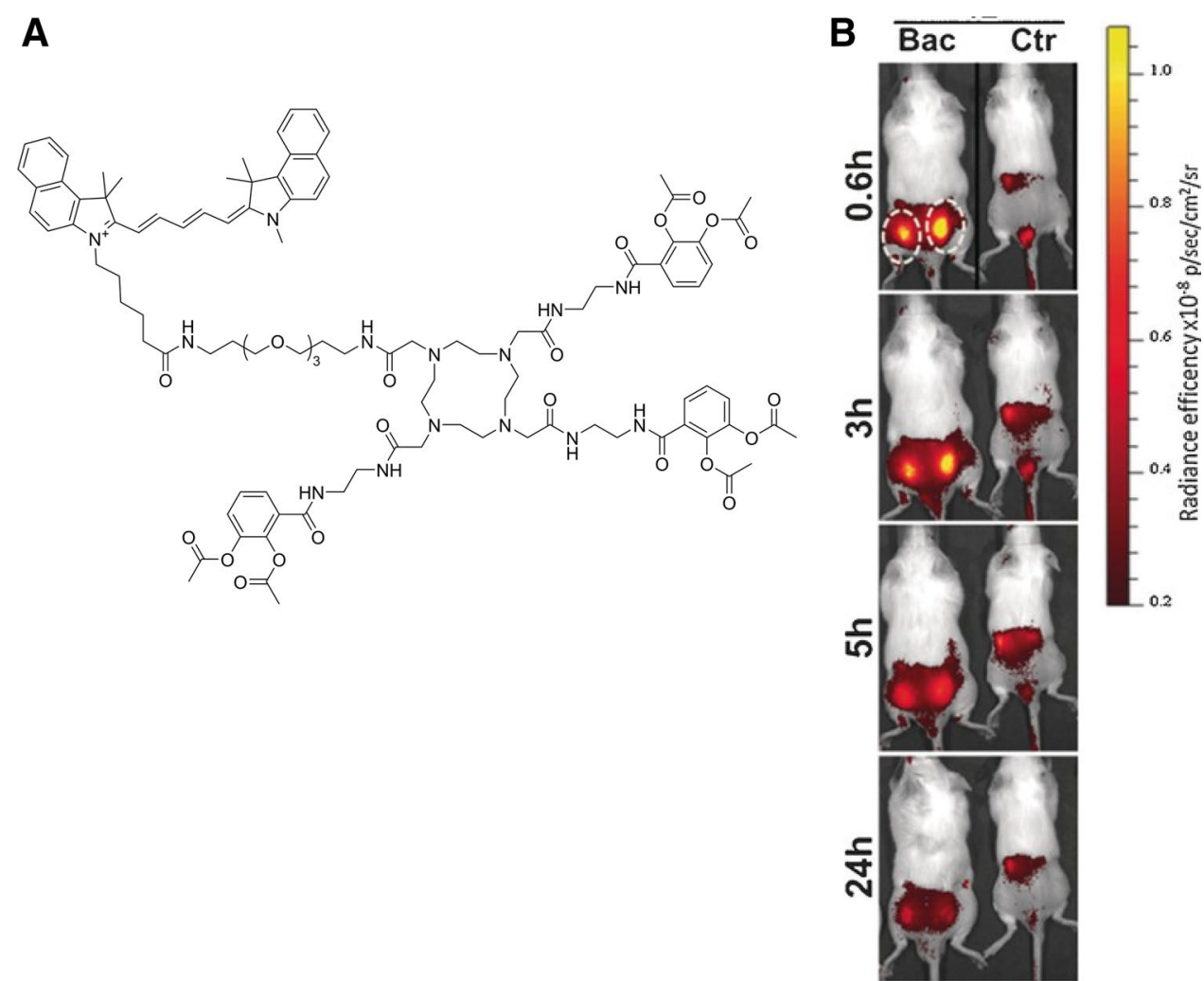

lies with tracers that are based on targeting vectors that are specific for bacteria: e.g., fluorescently labelled $\mathrm{UBI}_{29-41}$, polymyxin $\mathrm{B}$, vancomycin, ZnDPA and a M. tuberculosisspecific $\beta$-lactamase-cleavable linker CNIP800. Multimodal concepts using dually labelled $\mathrm{UBI}_{29-41}$, vancomycin, and ZnDPA help connect optical imaging to the more traditional use of radiopharmaceuticals in infectious diseases. Multimodal bacterial imaging is a promising strategy not only to diagnose bacterial infections but also to evaluate the effectivity of surgical treatment for infections. Although the recent developments are promising regarding imaging of specific bacterial species (Gram-positive or Gram-negative strains), it must be considered that bacterial imaging tracers as we described in this review cannot discriminate between antibiotic-sensitive or -resistant bacterial strains. Therefore, further research in exploiting molecular targets may support the discrimination between bacterial species and those that are unique to resistance properties.

Altogether, pre-clinical development and evaluation of dual-labelled bacteria imaging radiopharmaceuticals for 

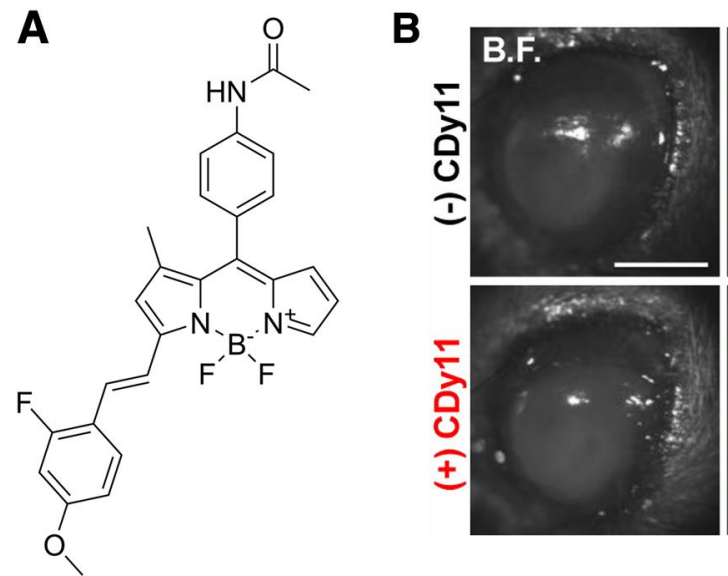

Fig. 12 a Chemical structure of CDy11. b In vivo imaging of bacterially infected eyes with CDy11. Green fluorescence signals were detected for the $P$. aeruginosa (PAO1-GFP) infected eye (bottom pan-

SPECT/PET and optical imaging is still in progress and the first results shows great promise, but as for every new compound, further studies concerning specificity, sensitivity, and safety assessments including toxicity and dosimetry are required.

Acknowledgements The research leading to these results was funded with grants from the Netherlands Organization for Scientific Research (VIDI Grant-STW BGT11272 to F. W. B. van Leeuwen and 864.10.003 to Wiep Klaas Smits), Meta Roestenberg was supported by a VENI Grant from ZONMW and a Gisela Thier fellowship from the LUMC.

\section{Compliance with ethical standards}

Conflict of interest The authors have declared that no competing interest exists.

Ethical standards In the selected clinical literature manuscripts were only included when all procedures followed were in accordance with the ethical standards of the responsible committee on human experimentation (institutional and national) and with the Helsinki Declaration of 1975 , as revised in 2008 .

Informed consent Informed consent was obtained from all patients for being included in these studies.

Open Access This article is distributed under the terms of the Creative Commons Attribution 4.0 International License (http://creativeco mmons.org/licenses/by/4.0/), which permits unrestricted use, distribution, and reproduction in any medium, provided you give appropriate credit to the original author(s) and the source, provide a link to the Creative Commons license, and indicate if changes were made.
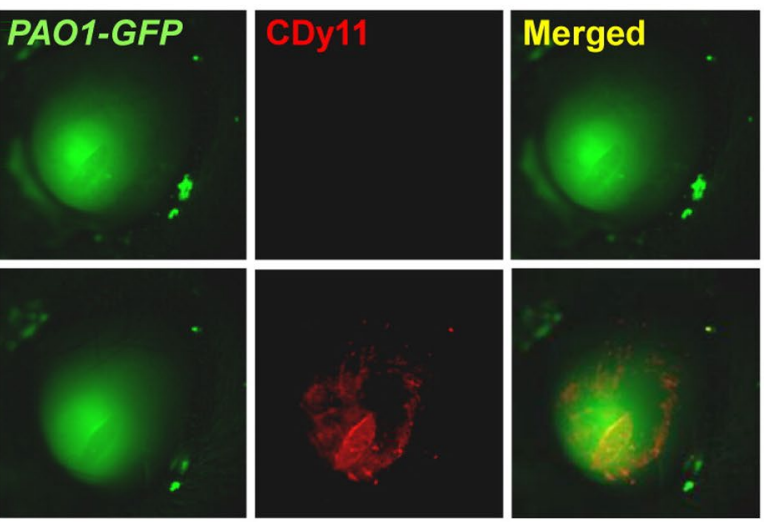

els). No fluorescent signals were detected in P. aeruginosa infected eyes without CDy11 (top panels). From: Jun-Young Kim et al. J Am Chem Soc. 2016;138:402-407

\section{References}

1. Mohajer MA, Darouiche RO (2014) The expanding horizon of prosthetic joint infections. J Appl Biomater Funct Mater 12(1):1-12

2. Palestro CJ, Love C, Miller TT (2007) Diagnostic imaging tests and microbial infections. Cell Microbiol 9(10):2323-2333

3. Gemmel F, Van den Wyngaert H, Love C, Welling MM, Gemmel P, Palestro CJ (2012) Prosthetic joint infections: radionuclide state-of-the-art imaging. Eur J Nucl Med Mol Imaging 39(5):892-909

4. Gemmel F, Dumarey N, Welling M (2009) Future diagnostic agents. Semin Nucl Med 39(1):11-26

5. Sasser TA, Avermaete AEV, White A, Chapman S, Johnson JR, Avermaete TV et al (2013) Bacterial infection probes and imaging strategies in clinical nuclear medicine and preclinical molecular imaging. Curr Top Med Chem 13(4):479-487

6. Bunschoten A, Welling MM, Termaat MF, Sathekge M, van Leeuwen FWB (2013) Development and prospects of dedicated tracers for the molecular imaging of bacterial infections. Bioconjug Chem 24(12):1971-1989

7. van Oosten M, Hahn M, Crane LMA, Pleijhuis RG, Francis KP, van Dijl JM et al (2015) Targeted imaging of bacterial infections: advances, hurdles and hopes. FEMS Microbiol Rev 39(6):892-916

8. Velikyan I (2018) Prospective of $68 \mathrm{Ga}$ radionuclide contribution to the development of imaging agents for infection and inflammation. Contrast Media Mol Imaging 2018:24

9. Leevy WM, Gammon ST, Johnson JR, Lampkins AJ, Jiang H, Marquez M et al (2008) Noninvasive optical imaging of staphylococcus aureus bacterial infection in living mice using a bis-dipicolylamine-Zinc(II) affinity group conjugated to a near-infrared fluorophore. Bioconjug Chem 19(3):686-692

10. DaCosta RS, Kulbatski I, Lindvere-Teene L, Starr D, Blackmore $\mathrm{K}$, Silver JI et al (2015) Point-of-care autofluorescence imaging for real-time sampling and treatment guidance of bioburden in chronic wounds: First-in-human results. PLoS ONE 10(3):e0116623

11. Rosochacki SJ, Matejczyk M (2002) Green fluorescent protein as a molecular marker in microbiology. Acta Microbiol Pol 51(3):205-216 
12. Mills B, Bradley M, Dhaliwal K (2016) Optical imaging of bacterial infections. Clin Transl Imaging 4(3):163-174

13. Ankrah AO, Klein HC, Elsinga PH (2018) New imaging tracers for the infected diabetic foot (nuclear and optical imaging). Curr Pharm Des 24(12):1287-1303

14. Leevy WM, Gammon ST, Jiang H, Johnson JR, Maxwell DJ, Jackson EN et al (2006) Optical imaging of bacterial infection in living mice using a fluorescent near-infrared molecular probe. J Am Chem Soc 128(51):16476-16477

15. White AG, Fu N, Leevy WM, Lee JJ, Blasco MA, Smith BD (2010) Optical imaging of bacterial infection in living mice using deep-red fluorescent squaraine rotaxane probes. Bioconjug Chem 21(7):1297-1304

16. Leevy WM, Lambert TN, Johnson JR, Morris J, Smith BD (2008) Quantum dot probes for bacteria distinguish Escherichia coli mutants and permit in vivo imaging. Chem Commun (Camb) 20:2331-2333

17. Liu CC, Gu YQ (2013) Noninvasive optical imaging of Staphylococcus aureus infection in vivo using an antimicrobial peptide fragment based near-infrared fluorescent probes. J Innov Opt Health Sci 6(3):1350026

18. van Oosten M, Schäfer T, Gazendam JAC, Ohlsen K, Tsompanidou E, de Goffau MC et al (2013) Real-time in vivo imaging of invasive- and biomaterial-associated bacterial infections using fluorescently labelled vancomycin. Nat Commun 4:2584.

19. Stone MRL, Butler MS, Phetsang W, Cooper MA, Blaskovich MAT (2018) Fluorescent antibiotics: new research tools to fight antibiotic resistance. Trends Biotechnol 36(5):523-536

20. Bardhan NM, Ghosh D, Belcher AM (2014) M13 virus based detection of bacterial infections in living hosts. J Biophoton 7(8):617-623

21. Ning X, Lee S, Wang Z, Kim D, Stubblefield B, Gilbert E et al (2011) Maltodextrin-based imaging probes detect bacteria in vivo with high sensitivity and specificity. Nat Mater 10(8):602-607

22. Disney MD, Zheng J, Swager TM, Seeberger PH (2004) Detection of bacteria with carbohydrate-functionalized fluorescent polymers. J Am Chem Soc 126(41):13343-13346

23. Hirschey MD, Han YJ, Stucky GD, Butler A (2006) Imaging Escherichia coli using functionalized core/shell CdSe/CdS quantum dots. J Biol Inorg Chem 11(5):663-669

24. Kong Y, Cirillo JD (2010) Reporter enzyme fluorescence (REF) imaging and quantification of tuberculosis in live animals. Virulence 1(6):558-562

25. Kong Y, Yao H, Ren H, Subbian S, Cirillo SL, Sacchettini JC et al (2010) Imaging tuberculosis with endogenous beta-lactamase reporter enzyme fluorescence in live mice. Proc Natl Acad Sci USA 107(27):12239-12244

26. Panizzi P, Nahrendorf M, Figueiredo J-L, Panizzi J, Marinelli B, Iwamoto Y et al (2011) In vivo detection of Staphylococcus aureus endocarditis by targeting pathogen-specific prothrombin activation. Nature Med 17:1142

27. Tang EN, Nair A, Baker DW, Hu W, Zhou J (2014) In vivo imaging of infection using a bacteria-targeting optical nanoprobe. $\mathrm{J}$ Biomed Nanotechnol 10(5):856-863

28. Rennie MY, Lindvere-Teene L, Tapang K, Linden R (2017) Pointof-care fluorescence imaging predicts the presence of pathogenic bacteria in wounds: a clinical study. J Wound Care 26(8):452-460

29. Hill R, Rennie MY, Douglas J (2018) Using bacterial fluorescence imaging and antimicrobial stewardship to guide wound management practices: a case series. Ostomy Wound Manag 64(8):18-28

30. Yin R, Dai T, Avci P, Jorge AES, de Melo WCMA, Vecchio D et al (2013) Light based anti-infectives: ultraviolet $C$ irradiation, photodynamic therapy, blue light, and beyond. Current Opin Pharmacol 13(5):731-762
31. Liu X, Cheng D, Gray BD, Wang Y, Akalin A, Rusckowski M et al (2012) Radiolabeled Zn-DPA as a potential infection imaging agent. Nucl Med Biol 39(5):709-714

32. Rice DR, Clear KJ, Smith BD (2016) Imaging and therapeutic applications of zinc(ii)-dipicolylamine molecular probes for anionic biomembranes. Chem Commun (Camb) 52(57):8787-8801

33. McPhee JB, Hancock RE (2005) Function and therapeutic potential of host defence peptides. J Pept Sci 11(11):677-687

34. Brender JR, McHenry AJ, Ramamoorthy A (2012) Does cholesterol play a role in the bacterial selectivity of antimicrobial peptides? Front Immunol 3:195

35. Glukhov E, Stark M, Burrows LL, Deber CM (2005) Basis for selectivity of cationic antimicrobial peptides for bacterial versus mammalian membranes. J Biol Chem 280(40):33960-33967

36. Ferro-Flores G, Avila-Rodríguez MA, García-Pérez FO (2016) Imaging of bacteria with radiolabeled ubiquicidin by SPECT and PET techniques. Clin Transl Imaging 4(3):175-182

37. Chen H, Liu C, Chen D, Madrid K, Peng S, Dong X et al (2015) Bacteria-targeting conjugates based on antimicrobial peptide for bacteria diagnosis and therapy. Mol Pharm 12(7):2505-2516

38. Akram AR, Avlonitis N, Lilienkampf A, Perez-Lopez AM, McDonald N, Chankeshwara SV et al (2015) A labelled-ubiquicidin antimicrobial peptide for immediate in situ optical detection of live bacteria in human alveolar lung tissue. Chem Sci 18(6):371-375

39. Welling MM, Bunschoten A, Kuil J, Nelissen R, Beekman FJ, Buckle T et al (2015) Development of a hybrid tracer for SPECT and optical imaging of bacterial infections. Bioconjug Chem 26(5):839-849

40. Tiyanont K, Doan T, Lazarus MB, Fang X, Rudner DZ, Walker $S$ (2006) Imaging peptidoglycan biosynthesis in Bacillus subtilis with fluorescent antibiotics. PNAS 103(29):11033-11038

41. Akram AR, Chankeshwara SV, Scholefield E, Aslam T, McDonald N, Megia-Fernandez A et al (2018) In situ identification of Gram-negative bacteria in human lungs using a topical fluorescent peptide targeting lipid A. Sci Transl Med 10(464):eaal0033

42. Velkov T, Thompson PE, Nation RL, Li J (2010) Structureactivity relationships of polymyxin antibiotics. J Med Chem 53(5): 1898-1916

43. Torres A, El-Ebiary M (2000) Bronchoscopic BAL in the diagnosis of ventilator-associated pneumonia. Chest 117(4 Suppl 2): $198 \mathrm{~s}-202 \mathrm{~s}$

44. Yang C, Ren C, Zhou J, Liu J, Zhang Y, Huang F et al (2017) Dual fluorescent- and isotopic-labelled self-assembling vancomycin for in vivo imaging of bacterial infections. Angew Chem Int Ed 56(9):2356-2360

45. Yang W (2011) Nucleases: diversity of structure, function and mechanism. Q Rev Biophys 44(1):1-93

46. Hernandez FJ, Huang L, Olson ME, Powers KM, Hernandez LI, Meyerholz DK et al (2014) Noninvasive imaging of Staphylococcus aureus infections with a nuclease-activated probe. Nat Med 20(3):301

47. Rosman CWK, Romero Pastrana F, Buist G, Heuker M, van Oosten M, McNamara JO et al (2018) Ex vivo tracer efficacy in optical imaging of Staphylococcus aureus nuclease activity. Sci Rep 8(1):1305

48. Roldan MD, Perez-Reinado E, Castillo F, Moreno-Vivian C (2008) Reduction of polynitroaromatic compounds: the bacterial nitroreductases. FEMS Microbiol Rev 32(3):474-500

49. Stanton M, Cronin M, Lehouritis P, Tangney M (2015) In vivo bacterial imaging without engineering; A novel probe-based strategy facilitated by endogenous nitroreductase enzymes. Curr Gene Ther 15(3):277-288

50. Elmes RBP (2016) Bioreductive fluorescent imaging agents: applications to tumour hypoxia. Chem Commun. 52(58):8935-8956 
51. Yang HJ, Kong Y, Cheng Y, Janagama H, Hassounah H, Xie H et al (2017) Real-time imaging of Mycobacterium tuberculosis, using a novel near-infrared fluorescent substrate. J Infect Dis 215(3):405-414

52. Nooshabadi F, Yang HJ, Cheng Y, Durkee MS, Xie H, Rao J et al (2017) Intravital excitation increases detection sensitivity for pulmonary tuberculosis by whole-body imaging with beta-lactamase reporter enzyme fluorescence. J Biophoton 10(6-7):821-829

53. Wright GD (2005) Bacterial resistance to antibiotics: enzymatic degradation and modification. Adv Drug Deliv Rev 57(10):1451-1470

54. Cuatrecasas P, Tell GP (1973) Insulin-like activity of concanavalin $\mathrm{A}$ and wheat germ agglutinin-direct interactions with insulin receptors. Proc Natl Acad Sci USA 70(2):485-489

55. Betton GR (1976) Agglutination reactions of spontaneous canine tumour cells, induced by concanavalin A, demonstrated by an isotopic assay. Int J Cancer 18(5):687-696

56. Sritharan M (2006) Iron and bacterial virulence. Ind J Med Microbiol 24(3):163-164

57. Ferreira K, Hu H-Y, Fetz V, Prochnow H, Rais B, Müller PP et al (2017) Multivalent siderophore-DOTAM conjugates as theranostics for imaging and treatment of bacterial infections. Angew Chem Int Ed 56(28):8272-8276

58. Zhou Y, Blanco LP, Smith DR, Chapman MR (2012) Bacterial amyloids. Methods Mol Biol (Clifton, NJ) 849:303-320

59. Kim J-Y, Sahu S, Yau Y-H, Wang X, Shochat SG, Nielsen PH et al (2016) Detection of pathogenic biofilms with bacterial amyloid targeting fluorescent probe, CDy11. J Am Chem Soc. 138(1):402-407

60. Alhede M, Bjarnsholt T, Jensen PO, Phipps RK, Moser C, Christophersen $\mathrm{L}$ et al (2009) Pseudomonas aeruginosa recognizes and responds aggressively to the presence of polymorphonuclear leukocytes. Microbiology 155(Pt 11):3500-3508

61. Azhdarinia A, Ghosh P, Ghosh S, Wilganowski N, Sevick-Muraca EM (2012) Dual-labeling strategies for nuclear and fluorescence molecular imaging: a review and analysis. Mol Imaging Biol 14(3):261-276

62. Seibold U, Wängler B, Schirrmacher R, Wängler C (2014) Bimodal imaging probes for combined PET and OI: recent developments and future directions for hybrid agent development. BioMed Res Int 2014:153741

63. Brouwer OR, van den Berg NS, Mathéron HM, van der Poel HG, van Rhijn BW, Bex A et al (2014) A hybrid radioactive and fluorescent tracer for sentinel node biopsy in penile carcinoma as a potential replacement for Blue Dye. Eur Urol 65(3):600-609

64. KleinJan GH, van Werkhoven E, van den Berg NS, Karakullukcu MB, Zijlmans H, van der Hage JA et al (2018) The best of both worlds: a hybrid approach for optimal pre- and intraoperative identification of sentinel lymph nodes. Eur J Nucl Med Mol Imaging 45(11):1915-1925

65. van den Berg NS, Valdes-Olmos RA, van der Poel HG, van Leeuwen FW (2013) Sentinel lymph node biopsy for prostate cancer: a hybrid approach. J Nucl Med 54(4):493-496
66. Rieffel J, Chitgupi U, Lovell JF (2015) Recent advances in higher-order, multimodal, biomedical imaging agents. Small 11(35):4445-4461

67. Criscione JM, Dobrucki LW, Zhuang ZW, Papademetris X, Simons M, Sinusas AJ et al (2011) Development and application of a multimodal contrast agent for SPECT/CT hybrid imaging. Bioconjug Chem 22(9):1784-1792

68. Welling MM, Hensbergen AW, Bunschoten A, Velders AH, Roestenberg M, van Leeuwen FWB (2019) An update on radiotracer development for molecular imaging of bacterial infections. Clin Transl Imag. https://doi.org/10.1007/s40336-019-00317-4

69. Bunschoten A, van Willigen DM, Buckle T, van den Berg NS, Welling MM, Spa SJ et al (2016) Tailoring fluorescent dyes to optimize a hybrid RGD-tracer. Bioconjug Chem 27(5):1253-1258

70. Kuil J, Buckle T, Yuan H, van den Berg NS, Oishi S, Fujii N et al (2011) Synthesis and evaluation of a bimodal CXCR70 antagonistic peptide. Bioconjug Chem 22(5):859-864

71. Bioinorganic Medicinal Chemistry (2011) In: Alessio E (ed) Wiley, Weinheim. https://doi.org/10.1002/9783527633104

72. Kuil J, Steunenberg P, Chin PTK, Oldenburg J, Jalink K, Velders $\mathrm{AH}$ et al (2011) Peptide-functionalized luminescent iridium complexes for lifetime imaging of CXCR72 expression. ChemBioChem 12(12):1897-1903

73. Ruggi A, van Leeuwen FWB, Velders AH (2011) Interaction of dioxygen with the electronic excited state of $\mathrm{Ir}(\mathrm{III})$ and $\mathrm{Ru}(\mathrm{II})$ complexes: Principles and biomedical applications. Coord Chem Rev 255(21):2542-2554

74. Rood MT, Oikonomou M, Buckle T, Raspe M, Urano Y, Jalink K et al (2014) An activatable, polarity dependent, dual-luminescent imaging agent with a long luminescence lifetime. Chem Commun (Camb) 50(68):9733-9736

75. Ruggi A, Beekman C, Wasserberg D, Subramaniam V, Reinhoudt DN, van Leeuwen FW et al (2011) Dendritic ruthenium(II)-based dyes tuneable for diagnostic or therapeutic applications. Chemistry (Weinheim an der Bergstrasse, Germany) 17(2):464-467

76. Steunenberg P, Ruggi A, van den Berg NS, Buckle T, Kuil J, van Leeuwen FW et al (2012) Phosphorescence imaging of living cells with amino acid-functionalized tris(2-phenylpyridine)iridium(III) complexes. Inorg Chem 51(4):2105-2114

77. Gutiérrez MI, Martínez CG, García-Fresnadillo D, Castro AM, Orellana G, Braun AM et al (2003) pSinglet oxygen ( $1 \Delta \mathrm{g})$ production by ruthenium(II) complexes in microheterogeneous systems. J Phys Chem A 107(18):3397-3403

78. Oster ZH, Som P, Gil MC, Fairchild RG, Goldman AG, Schachner ER et al (1981) Ruthenium-97 DTPA: a new radiopharmaceutical for cisternography. J Nucl Med 22(3):269-273

Publisher's Note Springer Nature remains neutral with regard to jurisdictional claims in published maps and institutional affiliations. 